\title{
Stateful library service system design and implementation in Saudi Arabia
}

\author{
Arif Bramantoro \\ Faculty of Computing and Information Technology in Rabigh, King Abdulaziz University, Saudi Arabia
}

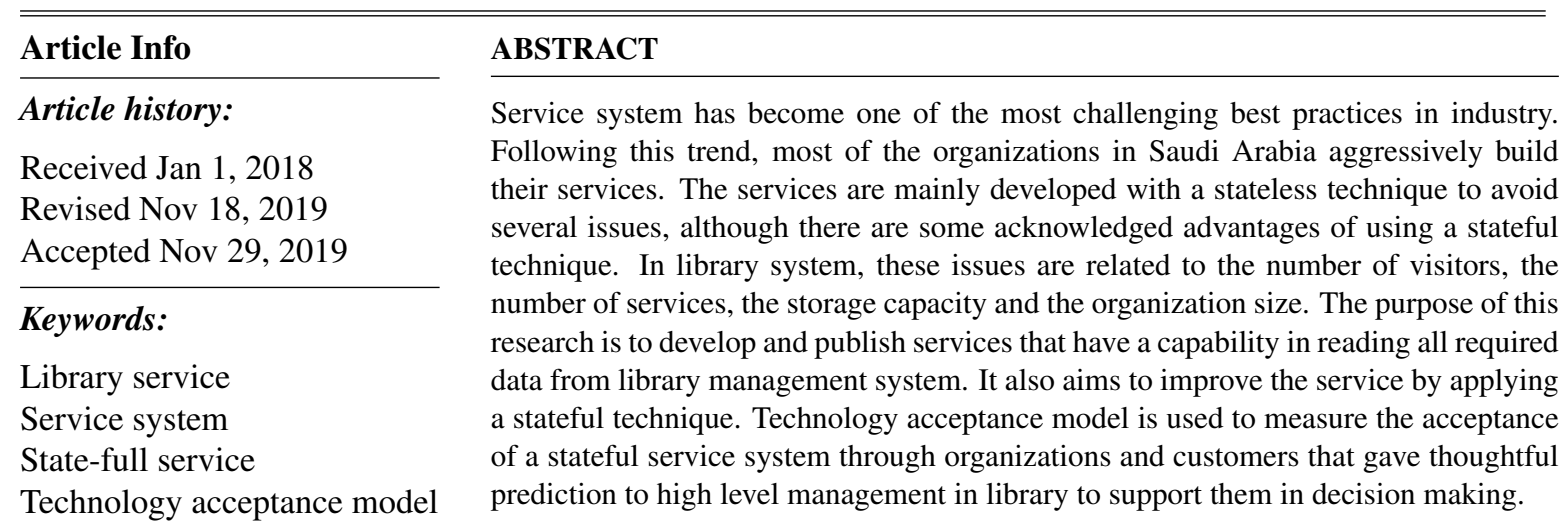

Copyright (c) 2020 Insitute of Advanced Engineeering and Science. All rights reserved.

\section{Corresponding Author:}

Arif Bramantoro,

Faculty of Computing and Information Technology in Rabigh,

King Abdulaziz University, Saudi Arabia.

Email: asoegihad@kau.edu.sa

\section{INTRODUCTION}

Service system, as initially coined in [1] and restored in [2], can be considered as a design and architecture of information systems based on isolated pieces of software, which is able to provide both legacy and innovative functionalities as services for seamless integration with other systems. Service system helps many organizations to merge their services to get the benefit of complete functionality which eventually inspired a more notable advance of cloud computing [3,4]. It aims not only to deploy new software or structure, but also enforces each organization to evaluate, cover its scope, establish the business processes and provide the best analysis. The works in [5,6] also emphasize that the organization has to prominently service their customers, partners and suppliers to reduce any negative impacts in the future.

Service system has been widely discussed among academics and practitioners. This is mainly because service system allows companies to reuse available components or services in order to build flexible system that implements disruptive business processes. Most enterprises continuously develop their systems for long term objective. These enterprises have a huge amount of data kept in the legacy systems, therefore neglecting these systems is not suitable. Service system provides a cost-effective solution and assists the services over a network [7]. The implementation of service system leads to deliver the service over the web. This is possible through the use of prominent technologies, such as Extensible Markup Language (XML) [8], Web Services Description Language (WSDL) [9], Business Process Execution Language (BPEL) [10], and Simple Object Access Protocol (SOAP) [11]. There have been proven implementations of service system in various areas, such as enterprise resource planning [12-14], internet of things [15-17], and data warehousing [18-20].

Service system has several benefits in order to support the business process and eventually increase the performance of organization, such as: 
(a) Providing a loosely coupled mechanism for application to be accessible anywhere by anyone.

(b) Enabling the application to application communication over the Internet.

(c) Enabling the combination amongst legacy applications that are wrapped as services to create composite services.

Service system provides the enterprise a restructurability of their business processes to increase the efficiency of the overall business activities. It also provides an adaptation of the dynamic requirements amongst the relevant competitors, and the enablement of the concept of everything as a service (XaaS) [21]. This service oriented approach transcends technology and automation solutions. It is an established and generic approach that can be used to address various problems. Service system represents open, reusable, agile, extensible, heterogenous, and ascertainable services. Hence, the implementation of service system based on its concepts and principles is inevitable.

This research represents the advantage of service system by building a real-life system. The stateful feature is embedded within the service to enhance the business process and its efficiency. The objective of the establishment of service system for most organizations is to provide a value added service to the customer. This is somewhat missing in the traditional systems that merely display the data without any service features.

The main purpose of this research is to construct service system with the stateful feature for library management system. Front end application is developed to call the services that read the required data from library management system. Then, the services are enhanced by applying a stateful technique. In detail, the contribution of this work is as follows:

(a) Streamline the integration between the proposed service system and the legacy system.

Legacy library management system is a system previously built by using the traditional mechanism and embedded with the implicit services. The management affirmatively believes that starting from scratch is the best solution and technique for successful implementation. The lack of adequate analysis and knowledge lead to additional investment, time and effort; whereas the reuse of existing resources significantly reduce the cost. The legacy functions in library management system are, therefore, wrapped over the Internet as service.

(b) Publish the library services with the stateful feature.

Front end application remains available for users, but it is granted an access to the newly published library services. The library services are stateful in order to allow the users to alternate between services without losing their important information.

(c) Improve the overall business processes with state-of-the-art information technology.

Most enterprises put their best efforts to provide a good solution or system that helps them to achieve their goals, increase productivity and build a bridge of trust with their stakeholders. A tangible feature is generally preferred by the stakeholders. Hence, it enables the organization to oversee their reactions. Stateful feature is able to carry out the stakeholder information and keep the services accessible from anywhere.

(d) Improve the ability to integrate various applications.

Either legacy or complex system can be used to get an advantage of its data, because there is no requirement to build a new system by migrating to service system. In service system, business process is transferred and restructured as a service available over the web. Preparing a suitable environment is beneficial to any organizations that facilitates the integration with other environments.

(e) Evaluate several factors before the decision of whether to use a stateful technique is made.

In the real world, there are several organizations that build their services based on either the stateful or stateless feature. Each organization has a specific reason to choose the best feature for its business and its customers who play a significant role during the decision making.

\section{STATEFUL LIBRARY SERVICE SYSTEM DEVELOPMENT STRATEGY}

There are four strategies that exist during the development of service system based on service oriented architecture principles [22]. The organisation relies on several considerations to choose the appropriate strategy. The first strategy is top-down. This strategy provides a high quality service system because the properties of each service are thoroughly analysed and the service reusability is maximized. It is an arduous task since it requires more effort and cost to deliver the right services. This strategy is considered useful when the new system is built. 
The second strategy is agile. This strategy is less manageable and more complicated than the other strategies. The business requirements should be intensively considered during the development. This strategy gains similar benefits to other strategies, but at the same time it lowers the risk of business requirements change.

The third strategy is bottom-up. This strategy focuses on legacy systems where the services are built. It plays on the role as a fundamental basis by fulfilling application-centric requirements. One of the drawbacks of this strategy is the lack of an advancement in service system, although it enables an immediate result and assists the integration with other systems. Because the objective of this research is to develop a library service system with the stateful feature based on the legacy system, this strategy is the most suitable.

Once the system development strategy is determined, the type of service system should be analysed. There are two fundamental types of service system: stateless and stateful service system. In stateless service system, the state of the service has insufficient persistence between subsequent requests and responses. Each request carries its user information and therefore it is individually authenticated. Simply put, a stateless service system is a system that handles each request as an independent transaction. One request is unrelated to any previous requests. Hence, there is no space for keeping the information after the request session is destroyed.

On the other hand, each request in the stateful service system recognizes any prior requests. All stateful requests are session-oriented which each request acknowledges and retains any changes made by previous requests. Therefore, the stateful service system is able to store any information regarding to the client and uses that information over a sequence of requests. The trade-off is that the stateless system has a better time performance than the stateful one.

The library service system enables service user to communicate to library management system through its stateful services. For example, buying and borrowing services are available to the service user from any programming interfaces. Hence, when the user changes her decision from borrowing the book to purchasing it, she is able to swap between these two services through a dynamic binding feature in service system. The user is just required to enter her information one time and it attaches to her.

In the stateful system, the behaviour of using the system is non-trivial. Hence, a traditional but yet powerful technology acceptance model [23] is chosen in this research to evaluate the library service system. The purpose of this model is to clarify the factors that can determine user's acceptance of technology as theoretically extended in [24]. This model requires a quantitative survey conducted by gathering data from users who are familiar with the services and distribute it through social media, email, and face-to-face discussion.

This research proposes five major factors in technology acceptance model applicable for library service system: perceived ease of use, website trust and security level, perceived usefulness, organization size, and attitude toward using. These five factors are important for the model to weigh the stateful and stateless service. In addition, the most important factors for users can be evaluated by the decision makers of library management.

\section{STATEFUL LIBRARY SERVICE SYSTEM DESIGN}

The service system design borrows several concepts from traditional modelling [25]. To the best of our knowledge, there are plenty of research gaps in service system modelling as also coined in [26]. Accordingly, the stateful library service is designed through the slight modification of traditional modelling techniques, such as service relationship, service instances, and workflow diagrams.

Service relationship diagram can be used as an effective method to communicate with other system analysts who have solved similar problems. This diagram illustrates the services that play an important role in the system as well as the relationship between them. In the service instance diagram, there are three service instances for library service: book information, borrowing and ordering services. These three service instances are detailed into several sub concrete services which represents the relationship between instances. These services are used to convert all database tables into service objects to facilitate the basic operational services: add, update and delete. Service user diagrams have the interaction between system and service users with available functionalities. Due to the limitation of the page, these diagrams are not shown in this paper.

The last diagram in service system design is for illustrating the service workflows. There are six service workflows to streamline the business process in the stateful library service system. The first workflow is to model the borrowing service process, where the service user searches, selects and adds the required book into her borrowing bag as illustrated in Figure 1(a). The second one is to model the borrowed books removal 
service process, where the service user checks her borrowing bag and removes unwanted books from her bag before submitting it to the library management as illustrated in Figure 1(b). The third workflow is to model the buying service process, where the service user searches, selects and adds the required book into her shopping cart as illustrated in Figure 1(c). The fourth workflow is to model the bought book removal service, where the service user searches, selects and removes the books from her cart before submitting it to library management as illustrated in Figure 1(d). The fifth workflow is to model the borrowed book request service, where the service user sends their request for the borrowed books as illustrated in Figure 1(e). The sixth workflow is to model the book order service, where the service user sends her order request as illustrated in Figure 1(f).

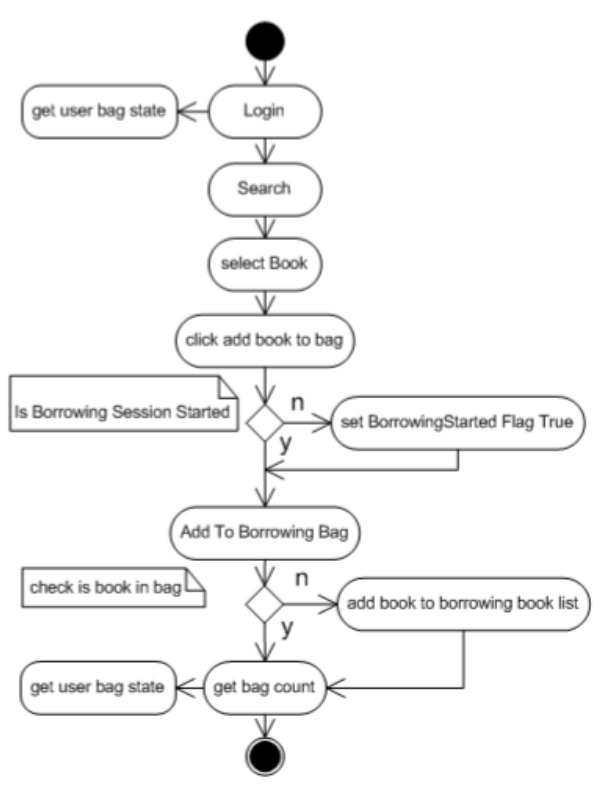

(a)

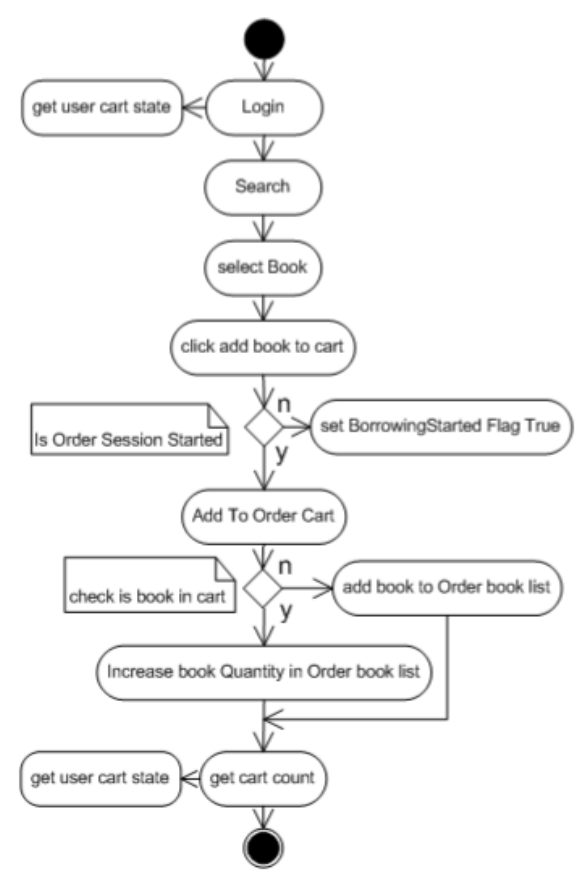

(c)

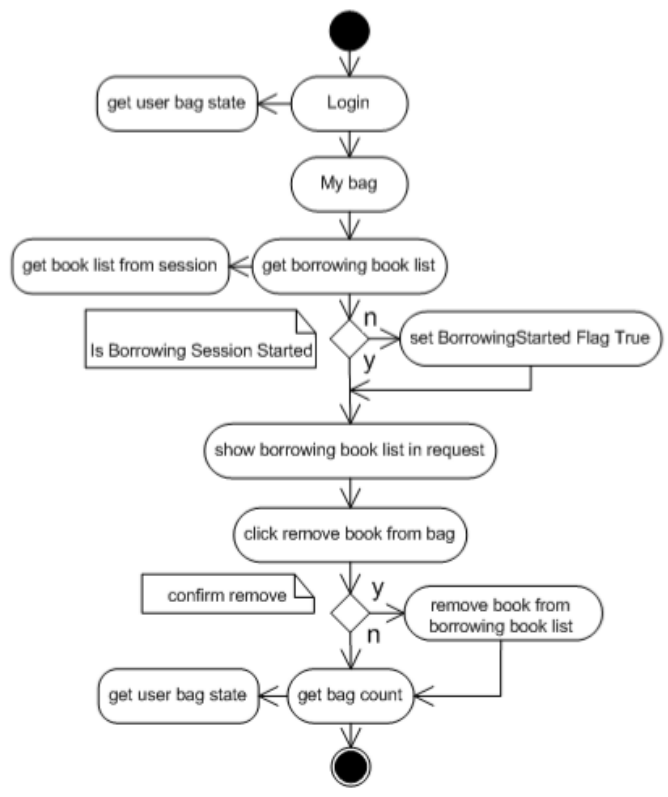

(b)

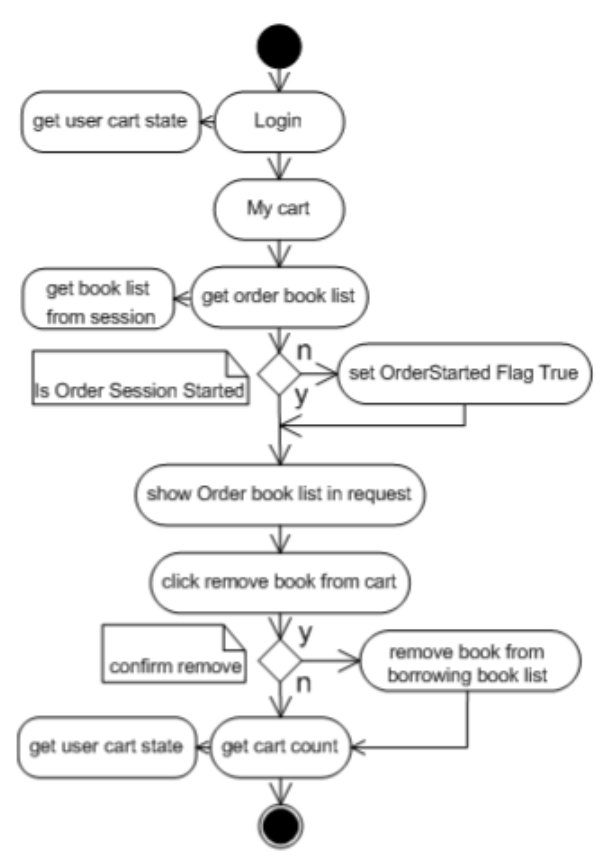

(d) 


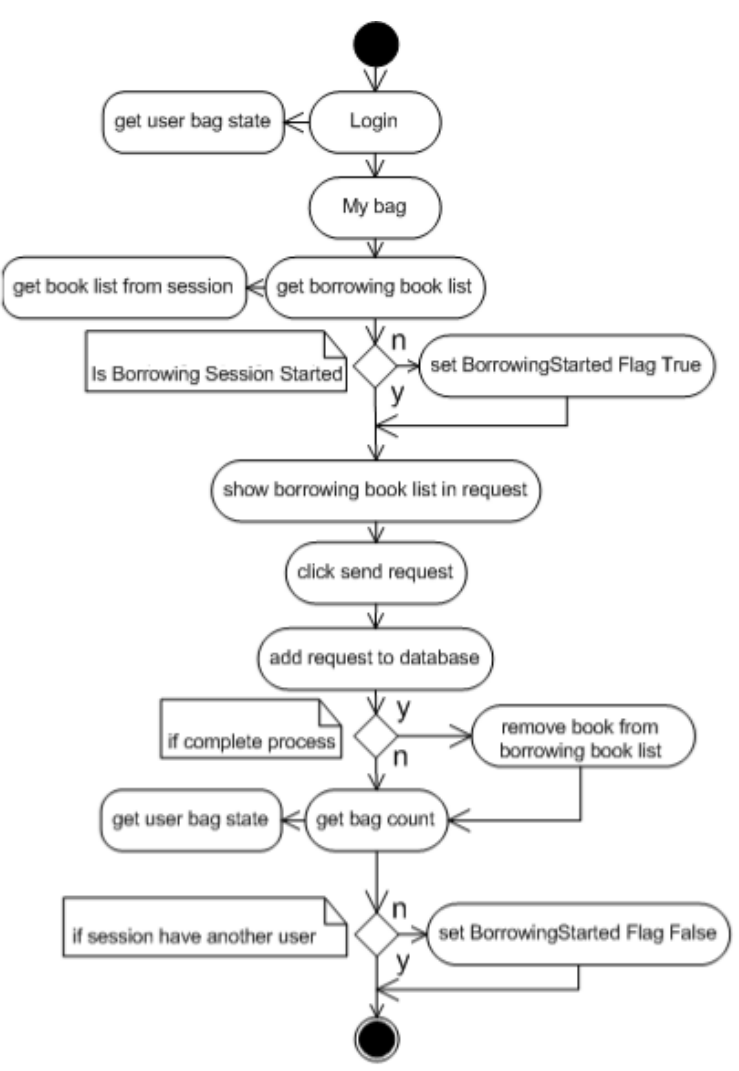

(e)

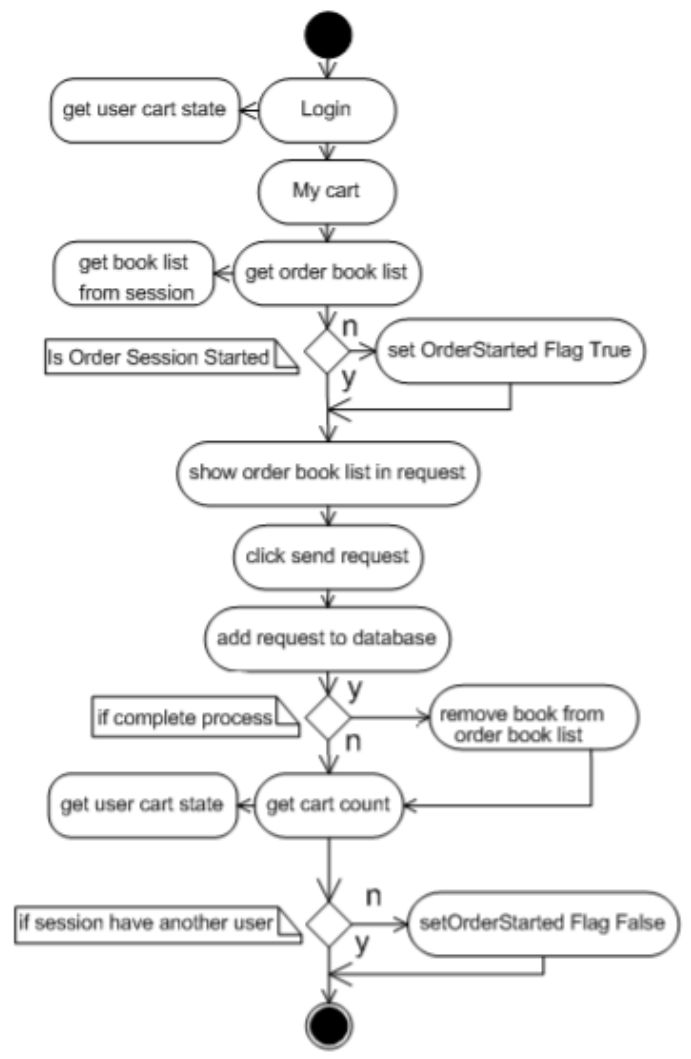

(f)

Figure 1. Library service workflows

To execute the published stateful library services, several front end interfaces are developed. One of them is illustrated in Figure 2, in which several books are selected and shown inside member's shopping cart, so that she can deal with these books and eventually update them by removing unwanted books before sending the request to the library management.

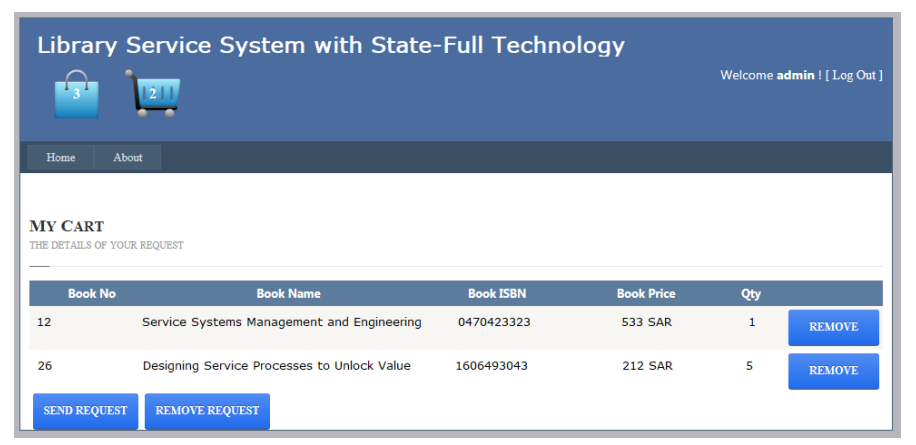

Figure 2. User interface for library service

\section{EVALUATION}

To evaluate the library service system, a new model based on technology acceptance model [23] is proposed to examine the behaviour of the system. The proposed model of five factors and their relationship is illustrated in Figure 3. It is important to note that only organization size factor is divided into two sub factors: number of services and customers, to ease the examination. 


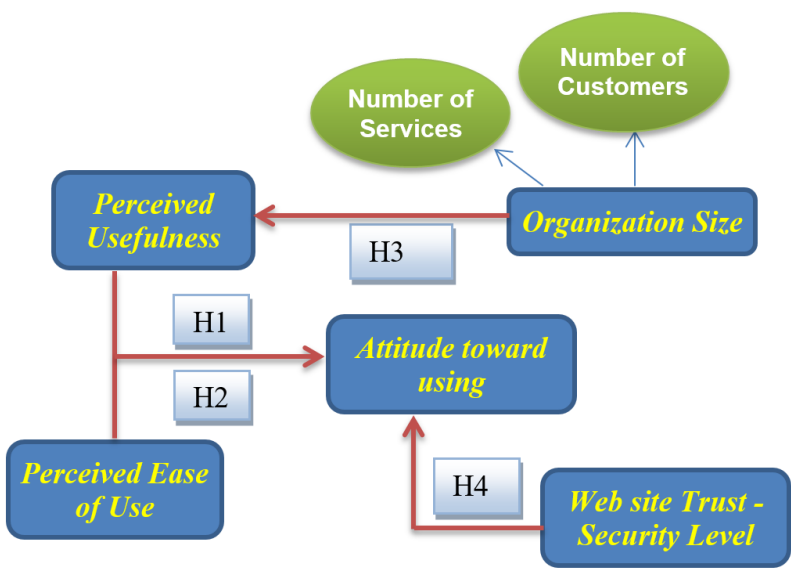

Figure 3. Stateful library service model

There are four hypotheses constructed in the proposed model as follows:

(a) Hypothesis $1(\mathrm{H} 1)$ : advantageous association of perceived usefulness and attitude toward using the stateful service.

(b) Hypothesis 2 (H2): advantageous association of perceived ease of use and attitude toward using the stateful service.

(c) Hypothesis 3 (H3): advantageous association of organization size (number of the stateful services) and perceived usefulness which can lead to increase customer's performance and disadvantageous relationship of organization size (number of customers) and perceived usefulness which can lead to impact the performance of organization.

(d) Hypothesis 4 (H4): advantageous association of application trust and security level and attitude toward using the stateful service.

The survey was distributed to 44 expert participants with minimum level of experience and knowledge. The small number of participants is chosen in order to focus on the topic of this research. The topic is very specific that requires a specialization of knowledge. All participants have information technology background with $57 \%$ master degree and $43 \%$ bachelor degree. There are approximately $64 \%$ who have seen the stateful service before and deal with it. Figure 4 summarizes the profile of the participants.
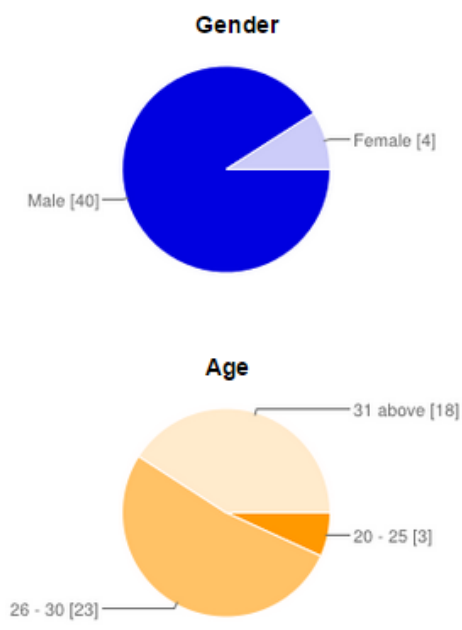
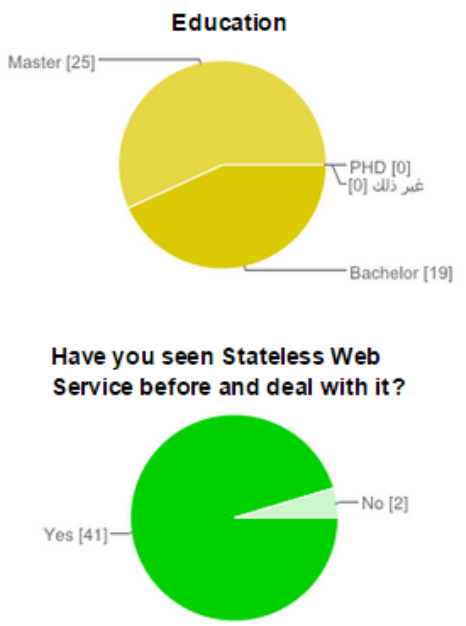

Figure 4. Survey participants profile

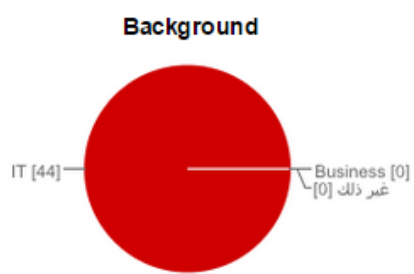

Have you seen State-full Web Service before and deal with it?

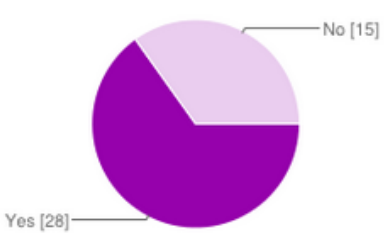


To verify the hypotheses, the participants were required to answer several questions related to each factor on a scale from 1 (very low) to 5 (very high). First, the participants were asked about the perceived usefulness as illustrated in Figure 5. It is the level of human belief that the use of library service system will improve the general performance. The perceived usefulness is associated to the productivity. It leads to the suggestion that the use of library service system in the workplace increases the production rate, improves the work performance, enhances the efficiency of work and benefits the work. However, it is interesting to note that only the perceived usefulness in term of difficulty in using the stateless feature has low result of maximum value (very high). It may lead to the conclusion that the concept of the stateless and stateful service is not acknowledged well by the participants.
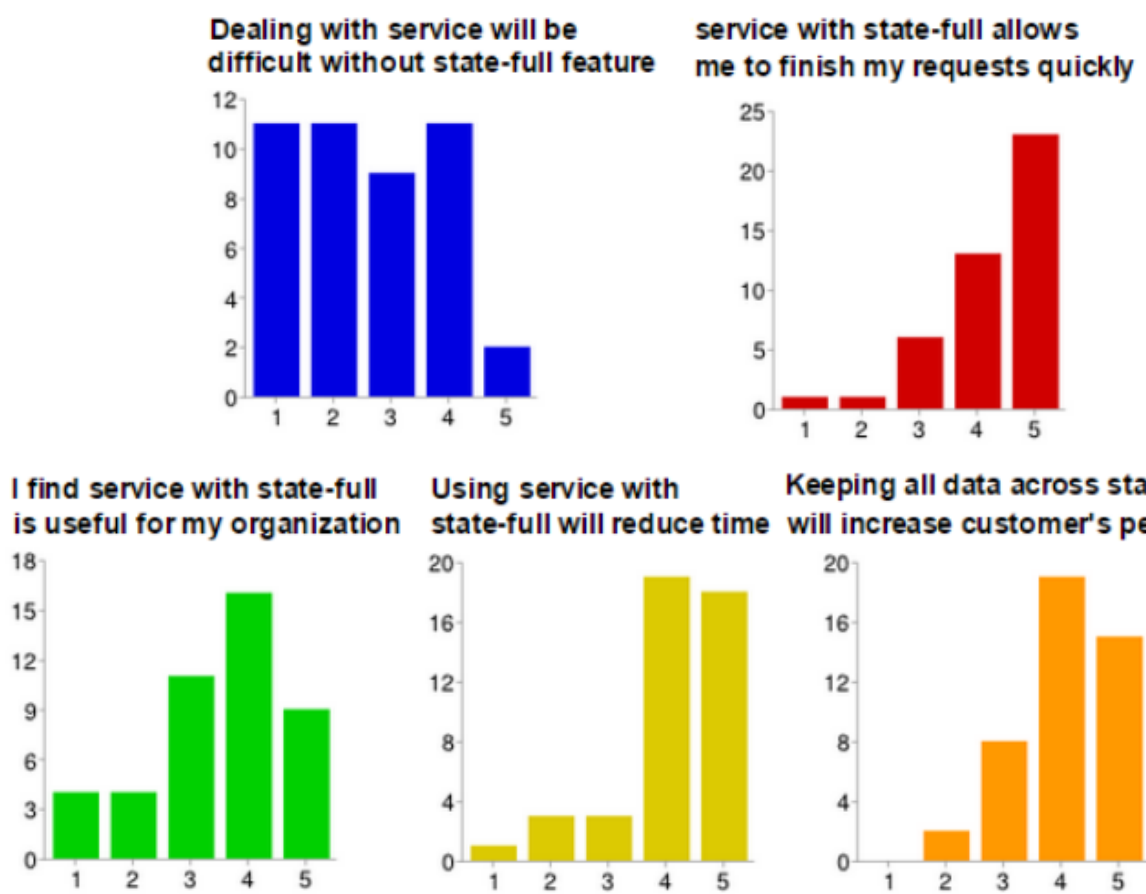

Keeping all data across state-full service will increase customer's performance

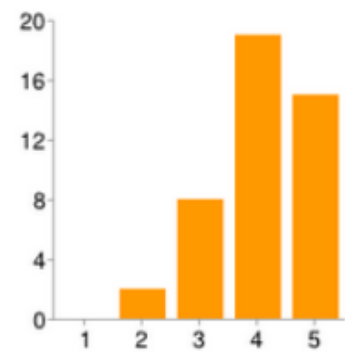

Figure 5. Perceived usefulness survey result

Second, the participants were asked about the perceived ease of use as illustrated in Figure 6. The perceived ease of use factor provides the level of human belief that she is able to use the system with a minimum effort. The higher believe in easily using the service is the more services that have been utilized. However, there is a contradictory result between two questions related to the efforts needed to interact. It is expected that there might be a confusion amongst the participants in differentiating between the effort to interact with the service and the effort in understanding the benefit given by the services.
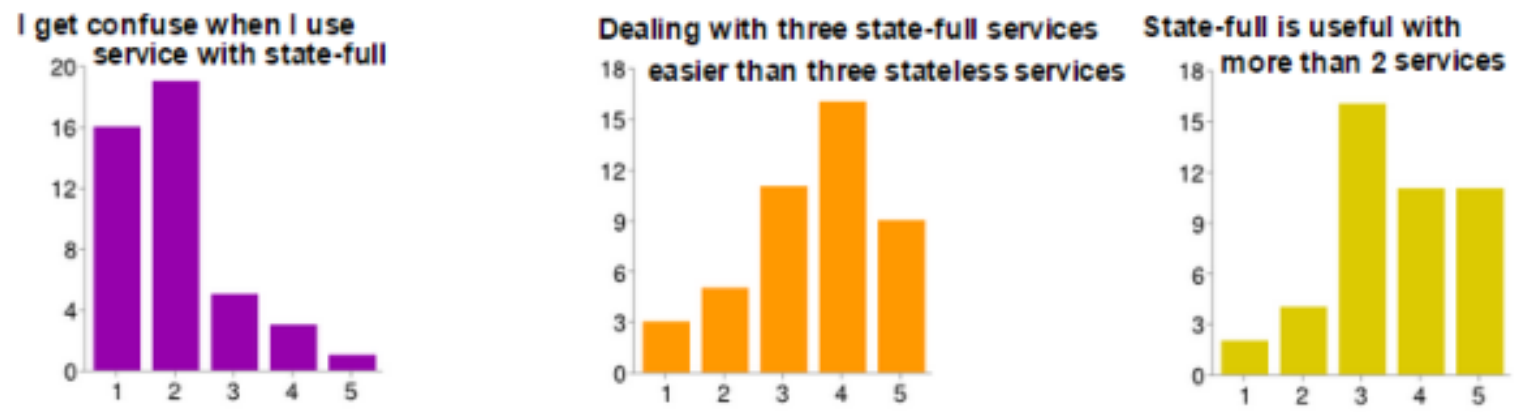

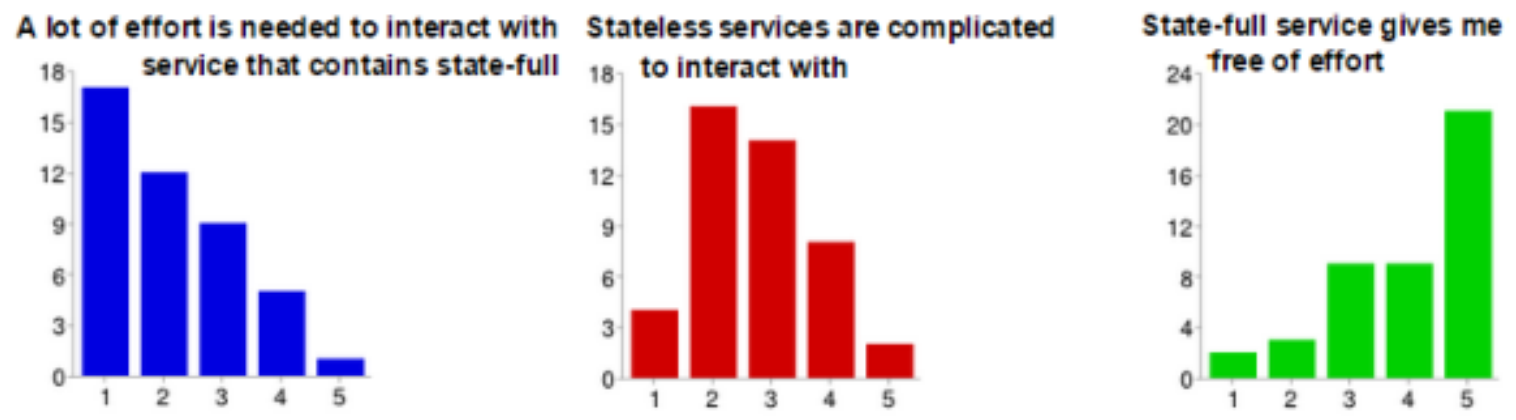

Figure 6. Perceived ease of use survey result

Third, the participants were asked about technological attitude as illustrated in Figure 7 . In this research, technological attitude is a measure of a person's desire to use the stateful services or not. Interestingly, similar pattern occurs in three questions: positive thinking, requirement satisfaction and positive feature. The lowest score is due to a bad experience and user interface. A relatively fair score is obtained which shows a similar preference for stateful and stateless.
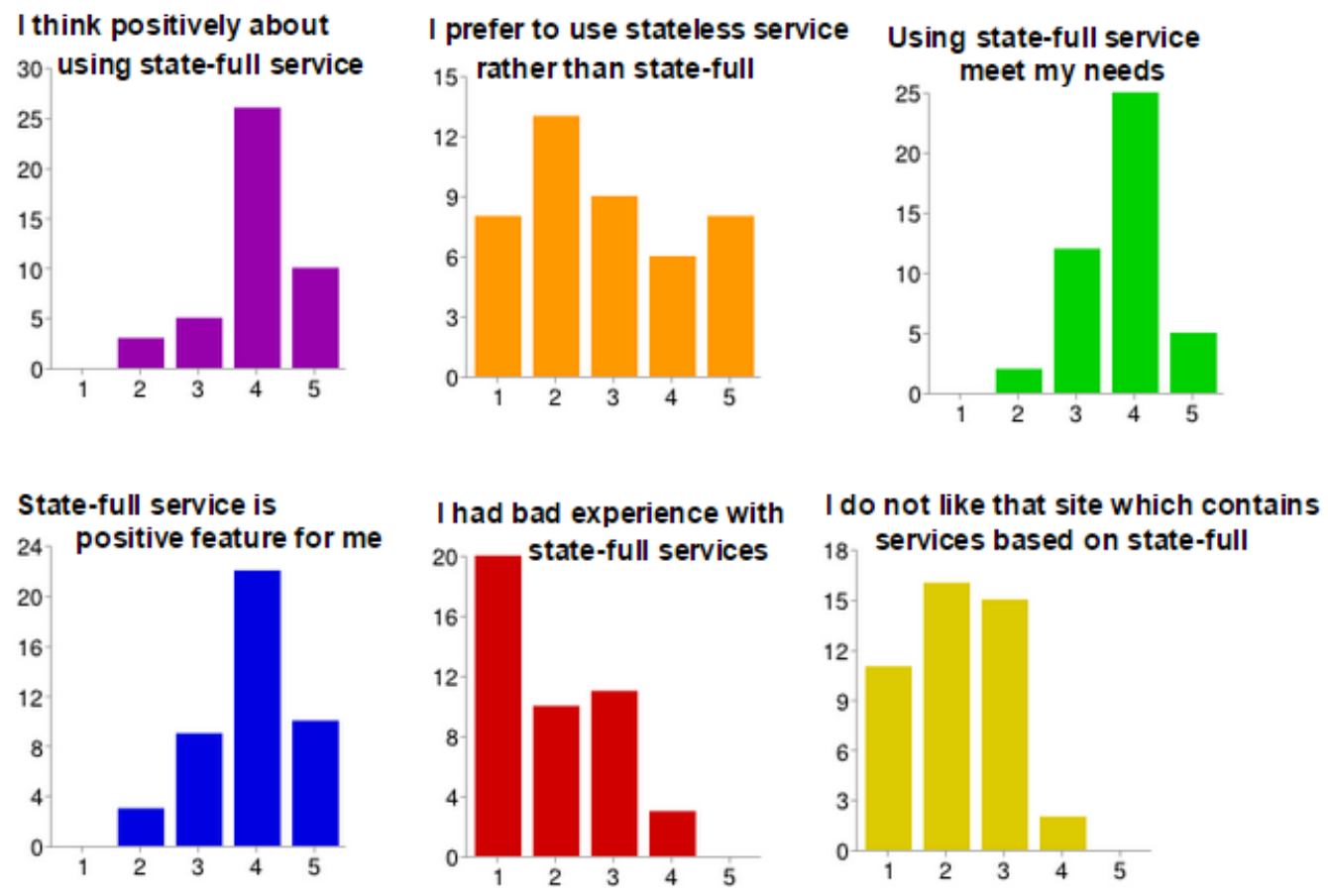

Figure 7. Attitude survey result

Fourth, the participants were asked about trust and security level as illustrated in Figure 8. It is a measure of a person's desire to use the stateful services based on how the services are guaranteed to be secure. It can be inferred that privacy and security are the main considerations for most participants. However, it remains unclear whether the confidential information is related to the stateful service or not. If the technology acceptance model provides a special technique to compare it with other technologies, it may lead to a different conclusion. Lastly, the financial condition is considered another reason for using the stateful service. This is understandable, due to several benefits of the stateful services as previously explained and demonstrated to the participants. 


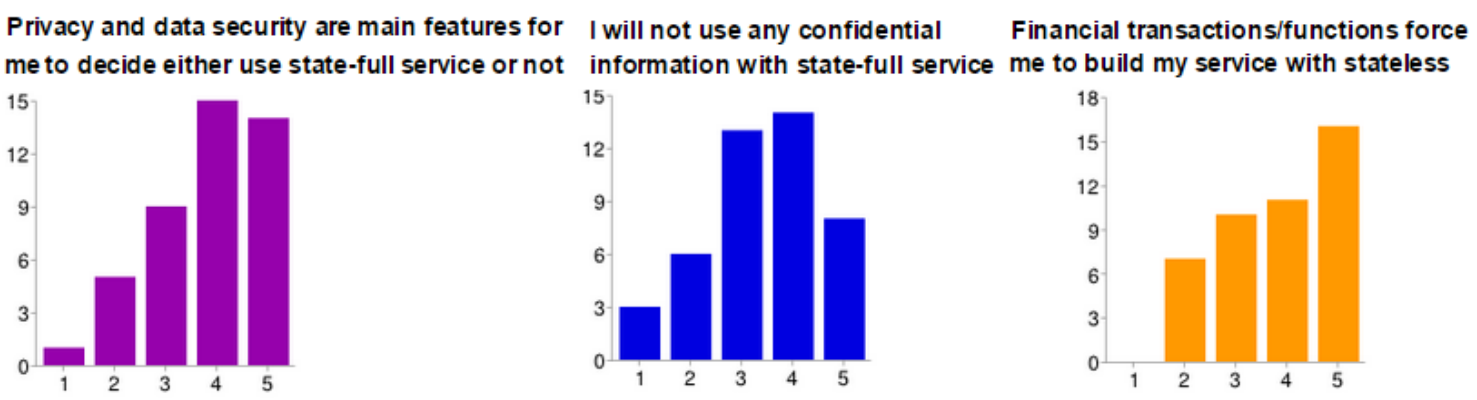

Figure 8. Trust and security level survey result

Fifth, the participants were asked about organization size as illustrated in Figure 9. It is a measure of a human's desire to use the stateful services based on the numbers of services that are being utilized and the number of customers who get the benefits of these services at the same time. Overall, there is only one factor that leads to the low satisfaction, which is the number of provided services.

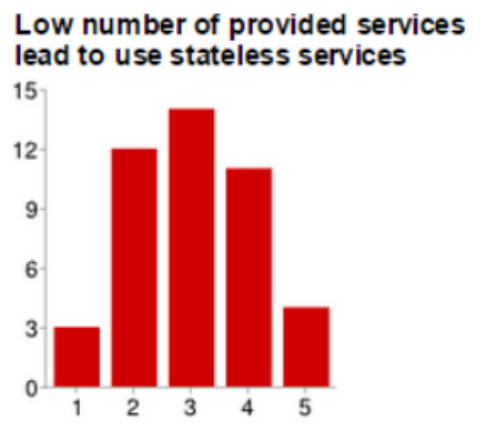

High number of customers lead to use
stateless services to avoid any impact
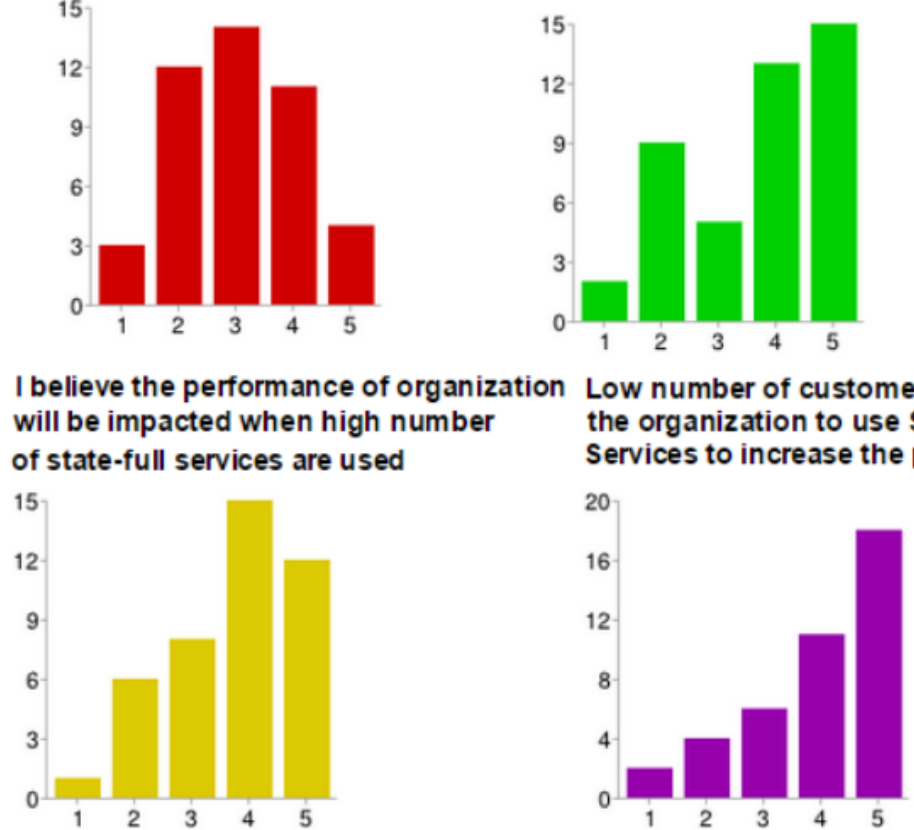

Figure 9. Organization size survey result

\section{CONCLUSION}

This research developed the library service system with the stateful technique that enables the service user to deal with the available services and acknowledge the value of them. A stateful feature complements any services that manages the explosion of data which are sometimes too complex for each execution of the services. Accordingly, a stateful library service system is developed in Saudi Arabia to store these data and therefore the user is able to easily alternate between available services. During the evaluation, there are two main concerns in building the service in stateful. The first concern is to focus on the customer and organization condition on which the library management have to balance between achieving their strategies and customer satisfaction. The second concern is to pay more attention to data privacy and security, because the modern users are more skilful and knowledgeable, and consequently their data are more sensitive. 


\section{ACKNOWLEDGEMENT}

This work was supported by the Deanship of Scientific Research (DSR), King Abdulaziz University, Jeddah, Saudi Arabia. The author, therefore, gratefully acknowledges the DSR technical and financial support. The author also thanks Homoud Al Homoud for conducting the experiments in Saudi Arabia.

\section{REFERENCES}

[1] P. P. Maglio, S. L. Vargo, N. Caswell, and J. Spohrer, "The service system is the basic abstraction of service science," Information Systems and e-business Management, vol. 7, no. 4, pp. 395-406, 2009.

[2] J. C. Spohrer, C. A. Kieliszewski, K. Lyons, P. P. Maglio, Y. Sawatani, and L. Patrício, Handbook of Service Science, Springer, 2019.

[3] A. T. Velte, T. J. Velte, R. C. Elsenpeter, and R. C. Elsenpeter, Cloud Computing: a Practical Approach, McGraw-Hill New York, 2010.

[4] Z. Á. Mann and V. Stolz, Advances in Service-Oriented and Cloud Computing, Springer, 2018.

[5] A. Bouguettaya, M. Singh, M. Huhns, Q. Z. Sheng, H. Dong, Q. Yu, A. G. Neiat, S. Mistry, B. Benatallah, B. Medjahed, et al., "A service computing manifesto: the next 10 years," Communications of the ACM, vol. 60, no. 4, pp. 64-72, 2017.

[6] L. Zhao, P. Loucopoulos, E. Kavakli, and K. J. Letsholo, "User studies on end-user service composition: a literature review and a design framework," ACM Transactions on the Web (TWEB), vol. 13, no. 3, p. $15,2019$.

[7] N. S. Bhuvaneswari and S. Sujatha, Integrating SOA and Web Services, River Publishers, 2011.

[8] "Extensible markup language (xml)," [Online]. Available: https://www.w3.org/XML/

[9] "Web services description language (wsdl) 1.1.," [Online]. Available: https://www.w3.org/TR/wsdl.html

[10] M. Hertis and M. B. Juric, "An Empirical Analysis of Business Process Execution Language Usage," IEEE Transactions on Software Engineering, vol. 40, no. 8, pp. 738-757, AUG 2014.

[11] "Latest soap versions," [Online]. Available: https://www.w3.org/TR/soap/

[12] A. Bramantoro, "Erp service for small and medium enterprises in saudi arabia," Indonesian Journal of Electrical Engineering and Computer Science, vol. 12, no. 1, pp. 69-77, 2018.

[13] R. Seethamraju, "Adoption of software as a service (saas) enterprise resource planning (erp) systems in small and medium sized enterprises (smes)," Information Systems Frontiers, vol. 17, no. 3, pp. 475-492, JUN 2015.

[14] G. Juell-Skielse and H. Enquist, "Implications of erp as service," Lecture Notes in Business Information Processing, vol. 105 LNBIP, pp. 129-151, 2012, cited By 5.

[15] H. G. Al-Majhad, A. Bramantoro, I. Syamsuddin, A. Yunianta, A. H. Basori, A. S. Prabuwono, and O. M. Barukab, "A traffic congestion framework for smart riyadh city based on iot services," International Journal of Advanced Computer Science and Applications, vol. 9, no. 4, pp. 292-303, 2018.

[16] C. Perera, A. Zaslavsky, P. Christen, and D. Georgakopoulos, "Sensing as a service model for smart cities supported by Internet of Things," Transactions on Emerging Telecommunications Technologies, vol. 25, no. 1, pp. 81-93, 2014. [Online]. Available: https://onlinelibrary.wiley.com/doi/abs/10.1002/ett.2704

[17] A. Urbieta, A. González-Beltrán, S. Ben Mokhtar, M. Anwar Hossain, and L. Capra, ”Adaptive and context-aware service composition for IoT-based smart cities," Future Generation Computer Systems, vol. 76, pp. 262-274, 2017, cited By 38.

[18] A. Bramantoro, "Data cleaning service for data warehouse: An experimental comparative study on local data," Telkomnika (Telecommunication Computing Electronics and Control), vol. 16, no. 2, pp. 834-842, 2018.

[19] A. Khan, S. Ghosh, and S. Ghosh, "edwaas: A scalable educational data warehouse as a service," Advances in Intelligent Systems and Computing, vol. 736, pp. 998-1007, 2018, cited By 2.

[20] N. Berkani, L. Bellatreche, and S. Khouri, "Towards a conceptualization of etl and physical storage of semantic data warehouses as a service," Cluster Computing-the Journal of Networks Software Tools and Applications, vol. 16, no. 4, pp. 915-931, DEC 2013.

[21] G. Li and M. Wei, "Everything-as-a-service platform for on-demand virtual enterprises," Information Systems Frontiers, vol. 16, no. 3, pp. 435-452, JUL 2014.

[22] N. B. Kurniawan, Suhardi, Y. Bandung, and P. Yustianto, "Services computing systems engineering framework: A proposition and evaluation through soa principles and analysis model," IEEE Systems 
Journal, pp. 1-12, 2019.

[23] F. D. Davis, "A technology acceptance model for empirically testing new end-user information systems: Theory and results," Ph.D. dissertation, Massachusetts Institute of Technology, 1985.

[24] V. Venkatesh and F. Davis, "A theoretical extension of the technology acceptance model: four longitudinal field studies," Management Science, vol. 46, no. 2, pp. 186-204, FEB 2000.

[25] T. Erl, SOA Principles of Service Design (paperback), Prentice Hall Press, 2016.

[26] J. Wang, H. Wang, J. Ding, K. Furuta, T. Kanno, W. Ip, and W. Zhang, "On domain modelling of the service system with its application to enterprise information systems," Enterprise Information Systems, vol. 10, no. 1, pp. 1-16, 2016.

\section{BIOGRAPHY OF AUTHOR}

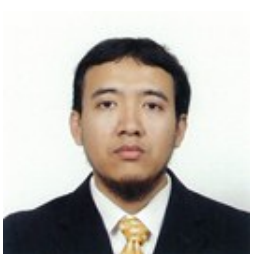

Arif Bramantoro is currently an associate professor in Faculty of Computing and Information Technology in Rabigh, King Abdulaziz University, Saudi Arabia. Previously, he was an expert researcher at Information Services Platform Laboratory, National Institute of Information and Communication Technology (NICT), Japan. He received PhD from Department of Social Informatics, Kyoto University in 2011. He holds master degree from Faculty of Information Technology, Monash University, Australia in 2005. His bachelor degree was obtained from Department of Informatics, Institute Technology of Bandung, Indonesia in 2001. He served as organizing committee of IEEE SERVICES CONGRESS 2012 in Honolulu, USA, program committee of ICoDIS 2017-2018 in Bandung, Indonesia; and reviewer at IEEE SCC and IEEE ICWS conferences; Elsevier COMPELECENG and SUSTAIN journals. His research interests include service system, business process workflow, and business intelligence. 